\title{
APUESTAS PARA UNA ECONOMÍA DIVERSIFICADA: LA INSERCIÓN DE LA UVA DE MENDOZA (ARGENTINA) EN MERCADOS EXTERNOS (1907-1930)*
}

\section{COMMITMENTS FOR A DIVERSIFIED ECONOMY: THE INSERTION OF MENDOZA GRAPE (ARGENTINA) IN FOREIGN MARKETS (1907-1930)}

\author{
Florencia Rodríguez Vázquez \\ Consejo Nacional de Investigaciones Científicas y Tecnológicas, Instituto de Ciencias Humanas, \\ Sociales y Ambientales, Mendoza, Argentina, frodriguezv@mendoza-conicet.gov.ar
}

Resumen. La economía provincial se caracterizó por la especialización en el monocultivo de vides y elaboración de vinos comunes para abastecer al mercado interno nacional (Litoral argentino). Sin embargo, desde las primeras décadas del siglo XX estuvo sujeta a crisis cíclicas, que alentaron las primeras propuestas para diversificar la agroindustria provincial. Entre ellas, resultaron notorias las iniciativas para comercializar uvas finas para consumo en fresco en los mercados internacionales. El objetivo de este artículo es estudiar los orígenes de la actividad, para ello reconstruiremos las trayectorias de los empresarios que incursionaron en forma temprana en el sector, cuáles fueron las estrategias para posicionar la producción y analizaremos la participación de los agentes estatales implicados en el fomento y promoción de la actividad.

Palabras clave: viticultura; uvas para consumo en fresco; exportación; empresarios.

Abstract. The provincial economy was characterized by its specialization in the monoculture of vines and elaboration of common wines to supply to the national domestic market (Argentinean littoral). However, since the first decades of the Xx century, the provincial economy was subject to cyclical crises, which encouraged the first proposals to diversify the provincial agribusiness. Among these, the most noteworthy proposals were the initiatives to commercialize fine grapes intended for fresh consumption in international markets. The objective of this article is to study the origins of this activity. In order to do that, we will reconstruct the path of the entrepreneurs who first forayed into the sector, see what were the strategies to position production, and will analyze the participation of the state agents involved in the advocacy and promotion of the commercialization activity.

Key words: viticulture; grapes intended for fresh consumption; export; entrepreneurs.

Fecha de recepción: 26 de septiembre de 2014. Fecha de aceptación: 3 de marzo de 2015.

* Trabajo elaborado en el marco de Proyecto de Investigación Pluridisciplinar del Consejo Nacional de Investigaciones Científicas y Técnicas (CONICET), dirigido por el doctor Rodolfo

Am. Lat. Hist. Econ., año 23, núm. 1, enero-abril, 2016, pp. 152-183 


\section{INTRODUCCIÓN}

$\mathrm{D}$ esde 1885 la vitivinicultura en las provincias de Mendoza y San Juan, de base capitalista, se organizó en torno al cultivo masivo de variedades (Malbec, Cabernet, Criollas) aptas para la elaboración de vinos comunes a gran escala, en bodegas tecnificadas. A partir de la extensión del tendido ferroviario, esta producción era comercializada exclusivamente en el mercado interno (Litoral argentino), de acuerdo con la demanda de la inmigración europea mediterránea (Barrio, 2003) (véase mapa 1). La promoción estatal fue decisiva en el proceso, que consolidó a Mendoza como núcleo regional de la actividad (véase cuadro 1). El espacio provincial quedó integrado, a partir de entonces, en un espacio funcional vinculado "perfectamente" con el resto del territorio nacional (Girbal-Blacha, 1987; Richard-Jorba, Pérez-Romagnoli, Barrio, Sanjurjo, 2006 , p. 23) y se consolidó como proveedor de esta bebida, formando, junto con San Juan, la región vitivinícola argentina. Si bien en décadas posteriores otras provincias se sumaron a la producción vitivinícola, su participación fue complementaria, confirmando así el peso destacado de Mendoza como núcleo productivo.

En la década de 1920 se elaboraron casi 5000 millones de litros de vino en la provincia, de los cuales $94 \%$-en promedio- se comercializaron fuera del mercado local (Anuario Estadístico de la Provincia de Mendoza, 1923-1931, p. 169) (véase cuadro 2). Esto guarda consonancia con la ampliación y consolidación de los desarrollos regionales que en ese periodo se integraban a un mercado interno creciente (Míguez, 2008, p. 311). Sólo una porción menor de la producción agrícola (uvas comúnmente denominadas Criollas o "de mesa") era destinada para consumo en fresco en los mercados locales. ${ }^{1}$

Sin embargo, prontamente, la excesiva especialización productiva fue un problema para el fortalecimiento de la economía regional y expuso a la provincia a crisis cíclicas desde las primeras décadas del siglo XX (19011903, 1914-1918, 1922) (Barrio, 2010). Estas coyunturas adversas plantearon la posibilidad de promover destinos alternativos para la uva: uno, como insumo en industrias derivadas (elaboración de mosto, jugo de uva, productos analcohólicos), y otro, para su consumo como fruta fresca. Por

Richard-Jorba, periodo: 2012-2014, y de la Secretaría de Ciencia Técnica y Posgrado, Universidad Nacional de Cuyo, dirigido por el doctor Eduardo Pérez Romagnoli, periodo: 2013-2015. La autora agradece las valiosas sugerencias de los evaluadores anónimos.

${ }^{1}$ Las estadísticas sobre producción vitícola disponibles no diferencian el porcentaje de variedades destinadas para vinificar (Vitis Vinífera), para consumo en fresco (comúnmente denominada Criolla, de mesa, Moscatel o Sanjuanina) en mercados locales y extranjeros (difundida como Alta Fantasía). 
MAPA 1. PROVINCIA DE MENDOZA. OASIS DE RIEGO, 1900

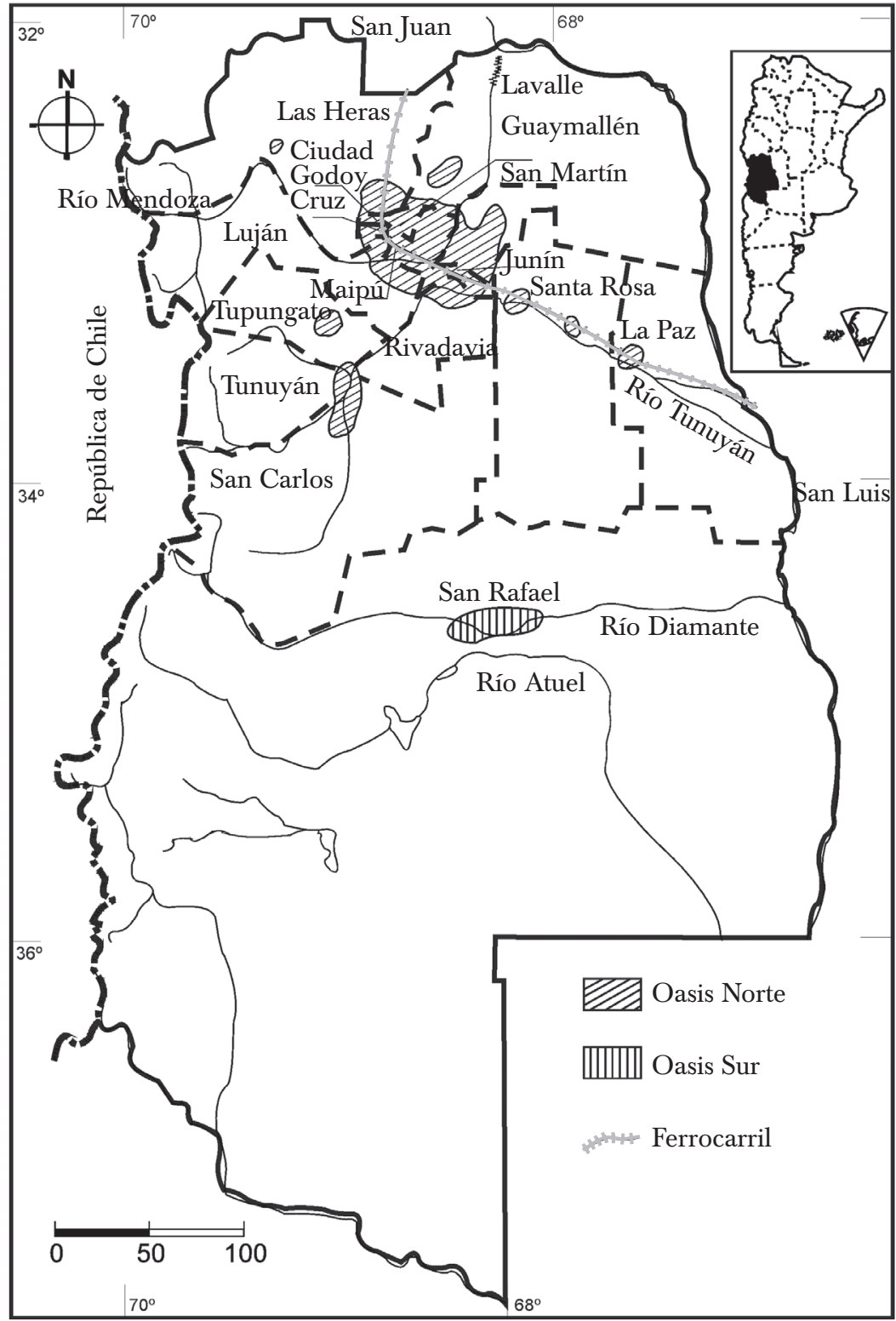

Fuente: diseño de Daniel Dueñas (Medios Audiovisuales y Gráficos, Centro Regional de Investigaciones Científicas y Tecnológicas, CONICET), en R. Richard-Jorba (1999). 


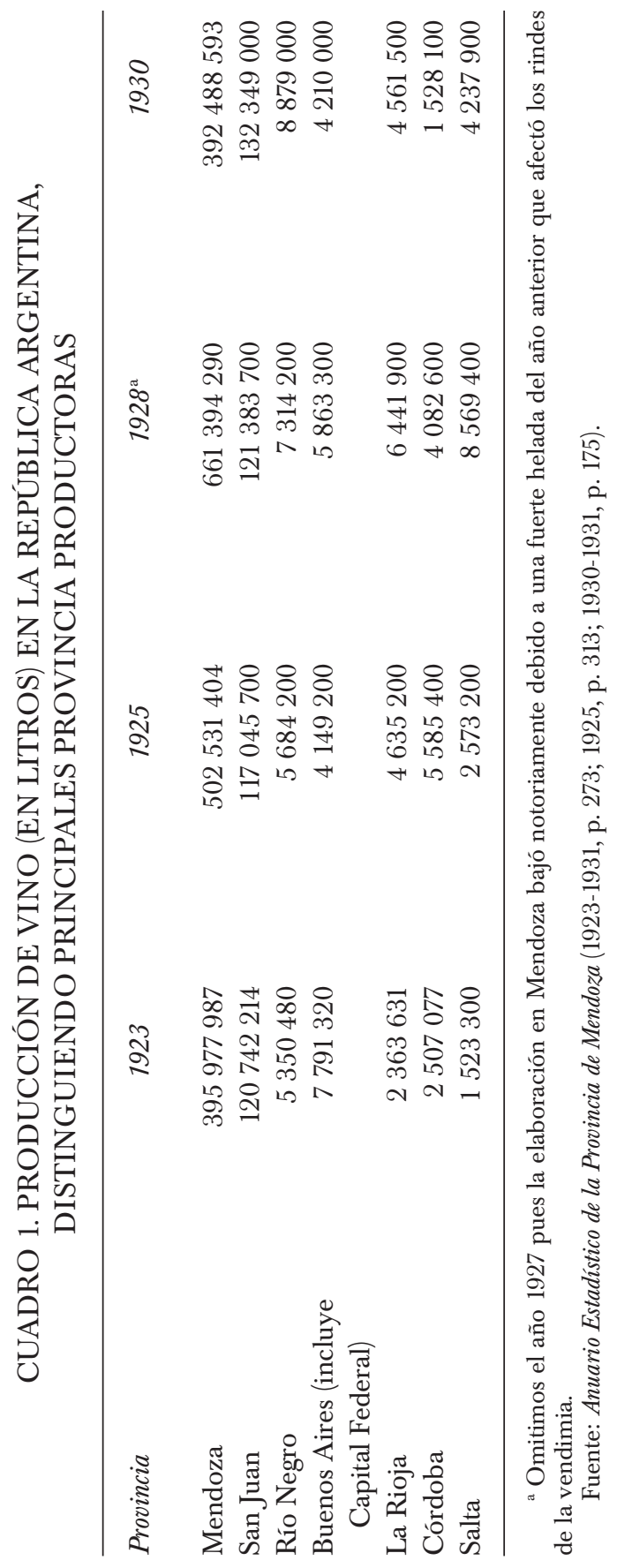




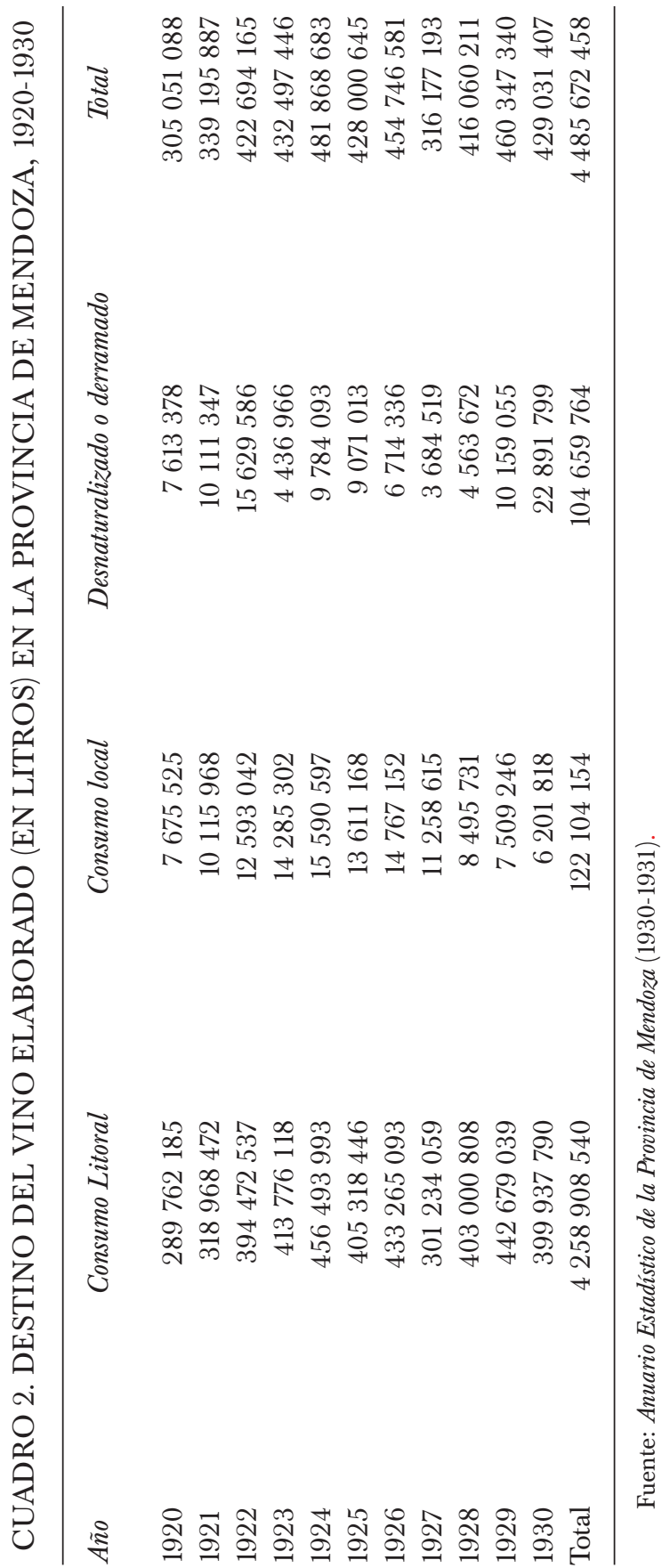


caso, durante la crisis de 1901-1903, el enólogo italiano Arminio Galanti fue un constante defensor y promotor de la diversificación de la vitivinicultura a través de la exportación de uva en fresco, la preparación de uva pasa y la elaboración de mosto concentrado y jugo de uva. Veremos que esta prédica sólo se concretaría en décadas posteriores.

Sobre esta base, en el presente trabajo ofreceremos una visión de conjunto de los orígenes de la exportación de uva en fresco en Mendoza durante la década de 1920, partiendo de la hipótesis de que agentes altamente capitalizados indujeron, dinamizaron y controlaron el sector, al margen de mecanismos efectivos de promoción estatal, los cuales sólo llegarían hacia finales de la década de 1920. Esta situación marcaría una diferencia con los orígenes de la vitivinicultura moderna en Mendoza, de base capitalista, extendida a partir de un sistema de exenciones impositivas para el cultivo del viñedo, entre 1881 y 1903 (Richard-Jorba, 2010), proceso durante el cual la elite dirigente, primero, y la burguesía regional (Balán, 1978), después, tuvieron una participación clave.

Si bien la comercialización de productos agropecuarios en mercados de ultramar había caracterizado a la región agroexportadora pampeana argentina (Barsky y Gelman, 2001), el caso mendocino imponía ciertas particularidades dadas las características de la uva y la distancia respecto al puerto. De modo que la exportación de uva fresca implicaba un importante desafío tecnológico para toda la cadena productiva y de comercialización en tanto que demandaba varias cuestiones: introducir y seleccionar nuevas variedades aptas para el consumo en fresco, organizar un sistema de empaque y traslado de la mercadería funcional al extenso recorrido que esta debería soportar, e incorporar un sistema de preenfriamiento y refrigeración de las partidas (desde la vendimia hasta la llegada al mercado de ventas) hasta entonces poco difundido en la provincia, así como también vincularse con agentes de venta extrarregionales. ${ }^{2}$ La inserción en mercados internacionales requería, a su vez, asegurar el control sanitario de las partidas y la injerencia estatal para flexibilizar los impuestos de las aduanas. Las cargas impositivas eran también un gran inconveniente para los viticultores mendocinos, puesto que la salida de uva hacia otras provincias estaba gravada, a fin de controlar la elaboración de vinos y el posible fraude en las plazas de consumo. Identificaremos, entonces, quiénes fueron los actores involucrados en la resolución de estos problemas.

Resulta oportuno mencionar que la atención de otras manifestaciones productivas -de base agrícola o industrial-reconoce escasos antecedentes

\footnotetext{
${ }^{2}$ Vale mencionar que los bodegueros dependían de compradores extrarregionales, quienes establecían el precio de la bebida e imponían, así, una estructura oligopólica que se podría haber extendido también para la venta de productos agrícolas.
} 
en la historiografía agraria regional (Rodríguez, 2014a, 2014b), salvo el estudio de las industrias derivadas, es decir, las que utilizan subproductos de la vinificación o la uva y el vino en sus producciones (elaboración de alcohol vínico, licores y ácido tartárico) (Pérez Romagnoli, 2010). Estas actividades surgieron a partir del excedente de materia prima. En estas iniciativas se ha destacado la participación de inmigrantes, muchos de ellos convertidos luego en empresarios regionales y la inversión de capitales extranjeros. Lacoste (2013, pp. 301-326), por su parte, hace una breve referencia sobre el cultivo de variedades para exportación a partir de la acción desarrollada por el Ferrocarril Buenos Aires al Pacífico (en adelante BAP). Para el caso sanjuanino se cuenta con algunos estudios para la década de 1930 (Arrabal de Jameson, 2014a, pp. 235-244, y 2014b, pp. 311-336). Estos aportes refieren una línea de estudio que problematiza la visión de las economías regionales como monoproductoras, carentes de cualquier estímulo diversificador (Moyano y Rodríguez, 2013). Por último, han resultado de interés aportes sobre los orígenes y consolidación de exportaciones de uva desde Almería (España) hacia Estados Unidos (Méndez, 1982; pp. 81-96; Marzo y Sánchez, 2006, pp. 116-142).

\section{PROPUESTAS DE DIVERSIFICACIÓN Y PROMOCIÓN ESTATAL: ALGUNOS ANTECEDENTES (1907-1918)}

El impulso a la exportación agrícola desde Mendoza en el periodo de estudio debe ser comprendido en el marco de un proyecto estatal provincial de diversificación de la actividad y complejización de la matriz económica productiva, que en forma temprana había procurado dar diversos usos a las hectáreas destinadas al cultivo agrícola, de modo de no sujetar la economía a una vitivinicultura presa de crisis cíclicas. En efecto, entre 19011903, 1913-1918 y 1922 la actividad se vio afectada por sobreproducción de materia prima, bajas en el precio de la uva y del vino, entre otros, que obligaron a la intervención del ejecutivo provincial para controlar la oferta de uva y la elaboración del vino. El estímulo a la diversificación agrícola en la década de 1920, a su vez, se explica por políticas procíclicas que, a partir de 1919, buscaron superar una larga depresión del sector que había afectado los planos social -baja de salarios y desocupación- y productivo -con destrucción de uvas y vinos comprados por el Estado, primero, y por el monopolio de la Compañía Vitivinícola, después (Richard-Jorba, 2013, pp. $71-101){ }^{3}$

${ }^{3}$ La Compañía Vitivinícola se trataba de un monopolio privado fiscalizado por el Estado. Se creó por Ley 703 (1 de diciembre de 1916) para la producción y la oferta de vino. Sus socios eran 
En forma previa, Emilio Civit ${ }^{4}$ había sostenido que el progreso económico de la provincia vendría a través de la promoción de nuevos cultivos cuya producción se consumiera como frutas o en conservas. Así fue que en 1908 el gobernador promulgó la Ley núm. 385 de exoneración de impuestos a los terrenos y cultivos de árboles frutales o de aplicación industrial. Sin embargo, su repercusión fue escasa (Rodríguez, 2014a) en relación con el exponencial incremento que habían experimentado los terrenos cultivados con vid entre 1881 y 1903. Al año siguiente, Civit contrató al enólogo francés Paul Pacottet para investigar distintos temas relacionados con la vitivinicultura y fruticultura. Por entonces, expresaba el gobernador que el cultivo de uvas de mesa -es decir, para su consumo en fresco y no para vinificar- era muy reciente y comprendía sólo variedades "comunes" (Moscatel blanco y rosado) destinadas al mercado interno.

Por su parte, en 1905 el Centro Vitivinícola Nacional (en adelante CVN) -entidad que nucleaba a los bodegueros más poderosos de la provincia y del país (Barrio, 2006; Ospital, 2013)- había manifestado que la exportación de uva en fresco de Mendoza a Europa era irrealizable debido, principalmente, al precio de las tarifas ferroviarias y a "la presencia de casas importadoras monopólicas instaladas en Buenos Aires", ${ }^{5}$ problemas que afectaban especialmente la comercialización de vinos en el mercado interno. Sólo en 1913, otro año crítico para la producción local, el CVN comenzó a referirse a los nuevos usos para la uva: consumo en fresco en el extranjero y elaboración de jugo de uva; también inició una importante prédica sobre industrialización de los subproductos de la uva (mostos, destilados, ácido tartárico). ${ }^{6}$ Estas propuestas, según el punto de vista de la corporación, permitirían remediar la crónica superproducción de uva, considerada una de las principales causas de la mencionada crisis. ${ }^{7}$ Cuatro años después, una comisión local -integrada por empresarios y políticos, y designada para estudiar la crisis vitivinícola- mencionó como aspectos problemáticos el excedente de uvas para vinificar y la falta de uvas de mesa para enviar al Litoral argentino (Day et al., 1917, pp. $27-28$ y 41-48; Barrio 2012, pp. 197-213), así como la necesidad de proyectar una política

la totalidad de los viñateros, vitivinicultores y bodegueros de la provincia, aunque las decisiones debían contar con la aprobación del ejecutivo provincial.

${ }^{4}$ Emilio Civit y su padre, Francisco, lideraron la oligarquía paternalista provincial, de corte liberal en lo económico y conservador en lo político, desde la década de 1870 (Pérez Guilhou, 1980, pp. 335-355). En estos años se aplicó, por primera vez, el poder estatal para promover la modernización de la viticultura (Richard-Jorba, 1998).

${ }^{5}$ Boletín del Centro Vitivinícola Nacional (en adelante BCVN), 16 de noviembre de 1905.

${ }^{6}$ BCVN, núm. 99, diciembre de 1913, pp. 2725-2726, y núm. 113, agosto de 1915, pp. 337-344.

${ }^{7}$ El diagnóstico de la entidad es parcial pues no menciona el estiramiento y procedimientos fraudulentos de elaboración de vino a través del agregado de sustancias no permitidas por la legislación vigente. Estas prácticas reducían el uso de uva en la elaboración. 
agraria que contemplara el fomento de nuevos cultivos. Ya se plasmaba, por entonces, la importancia de explotar las diversas posibilidades de la viticultura, en este caso, para su consumo como frutas y no destinar toda la producción a la elaboración de vinos.

Quizá como consecuencia de estos diagnósticos, el gobernador José Néstor Lencinas, en la asunción de su mandato (febrero de 1918) delineó diversos aspectos de un incipiente programa agrario (fomento de la agricultura, arboricultura frutal, fruticultura, introducción de nuevas variedades de vides y profundización en el control de elaboración) (Nieto Riesco, 1926, pp. 285-286), aunque con dificultades para su concreción en el corto plazo. Para promocionar nuevos cultivos y responder a los problemas que afectaban crónicamente a la vitivinicultura, ese año creó la Dirección de Fomento Agrícola e Industrial -sobre la base de la Dirección General de Industrias- (Boletín Oficial de la Provincia de Mendoza, Dto. 47, 10 de abril de 1918, pp. 1582-1583) bajo la conducción del enólogo Mario Bidone. La nueva administración intentó romper con la excesiva orientación que había tenido hacia la atención de las cuestiones vitivinícolas -en concreto, a través de mecanismos rigurosos de control y fiscalización-. De modo que uno de sus principales objetivos fue estimular diversos cultivos agrícolas y otras industrias (aprovechamiento de toda la materia prima) cuya producción se volcaría a nuevos mercados. Es probable que la recuperación general de la economía nacional alentara este proceso. Lencinas procuró, también, la difusión de nuevas variedades de vides, frutales y forestales e intensificar la industrialización del excedente de materia prima, organizando un sistema de propaganda y exposiciones temporarias, como sucedía en otras provincias (Di Liscia y Lluch, 2009). ${ }^{8}$ En este marco, además del fomento a la arboricultura forestal y la fruticultura, se daba especial impulso, por primera vez, a las variedades de uva de mesa para exportar. ${ }^{9}$

En 1922 la mencionada dependencia pasó a denominarse Dirección Provincial de Industrias. Su responsable, el enólogo italiano Arminio Galanti, se refirió en diversas ocasiones al aprovechamiento industrial de la uva para resolver el crónico excedente de materia prima, considerado una de las causas de la coyuntura de ese año. En la misma dirección, los indus-

${ }^{8}$ Las exposiciones han sido abordadas como eventos que permiten estudiar el reflejo y/o la mirada sobre las imágenes que cada país o grupo organizador forjaron de sí mismos, así como sobre los símbolos y objetos implicados en la construcción de su propia nacionalidad y proyección internacional. Además, constituían un lugar de contacto y sociabilidad entre los productores para intercambiar información técnica novedosa (Di Liscia y Lluch, 2009, p. 9).

${ }^{9}$ Mensaje del gobernador de la provincia de Mendoza, doctor José Nestor Lencinas, al inaugurarse el periodo de sesiones de la Legislatura, 1 de junio de 1918 (Nieto, 1926, p. 292). La extinta entidad había sido inaugurada en 1910 como un organismo técnico de control y fiscalización de la elaboración vínica, principal fuente de ingresos impositivos para las finanzas estatales. Parte de su gestión ha sido reconstruida por Barrio (2010). 
triales denunciaban que varios quintales podrían quedar sin colocación en las bodegas, así como también las consecuentes maniobras especulativas para fijar el precio de la materia prima y su depreciación. ${ }^{10}$

En ese contexto crítico se inició una ferviente prédica para el fomento de industrias derivadas de la vitivinicultura,${ }^{11}$ incluso Galanti dirigió una fábrica de productos analcohólicos (bebidas y alimentos sin alcohol) en el departamento de Godoy Cruz (Pérez Romagnoli, 2010, pp. 82-83), aunque sin éxito. Los técnicos también se sumaron a las propuestas sobre el uso diversificado de la materia prima ${ }^{12}$ y sugerían incursionar en nuevos mercados. Por ejemplo, el agrónomo Pedro Anzorena sugería la venta de vino y los derivados de la uva en países limítrofes (Brasil, Uruguay y Paraguay). Por su parte, el gobierno provincial y algunas empresas que operaban en la provincia aconsejaban la exportación de uvas de mesa a Estados Unidos, "un mercado remunerativo".

En suma, registramos desde 1908 un contexto discursivo en el cual la diversificación de la economía agrícola se posicionaba como una solución para atemperar, a largo plazo, los efectos de las crisis que afectaban al sector vitivinícola. Este proyecto, que trascendió etapas políticas y económicas de la provincia, se encontraba respaldado por un aparato burocrático que se modernizaba creando nuevas dependencias técnicas e incorporando profesionales altamente capacitados -químicos, enólogos, agrónomos- dentro y fuera del país.

No obstante, los objetivos de esta prédica y la introducción de cambios organizacionales en el seno de las dependencias se diluyeron frente a las escasas disposiciones del gobierno provincial que incidieran, en forma directa, en el incremento de las superficies cultivadas con variedades de vides para consumo en fresco. Sólo algunas disposiciones de 1914 y 1916 establecieron una especificidad técnica: el cultivo de vides debía realizarse con injerto de pie americano y sólo tras la autorización del ejecutivo provincial, pero no incorporaban requisitos acerca del tipo de variedades a cultivar ya que su principal objetivo era controlar probables focos de filoxera. ${ }^{13}$ El seguimiento de la aplicación de esas normas entre 1920 y 1923, a través de la consulta de decretos y resoluciones que concedían permiso para cultivar, demuestra que se extendió la práctica del portainjertos

${ }^{10}$ Los Andes, 3 de febrero de 1922, p. 5.

${ }^{11}$ Mensaje de los proyectos de ley sancionadas luego con los números 758 y 759, en septiembre de 1919 (Provincia de Mendoza, 1925, pp. 4885-4886); véase también Lemos (1922, pp. 66-77).

${ }^{12}$ Revista Mensual del BAP, núm. 50, enero de 1922, pp. 21-22.

${ }^{13}$ Registro Oficial de la Provincia de Mendoza, Ley núm. 646, 9 de noviembre de 1914; Ley núm. 703, 1 de diciembre de 1916. Ambas fueron sustituidas por la Ley núm. 810, 17 de febrero de 1923. 
para viñedos nuevos y reconstituidos. Por otro lado, aporta información sobre las variedades difundidas: se mantuvo vigente el predominio de las comunes, de baja aptitud enológica para vinificar, seguidas de aquellas para consumo en fresco, aunque con una clasificación que no respondía a criterios técnicos estrictos (Criolla, Sanjuanina, Moscatel rosado, "uva de mesa"). Dentro de este grupo, sólo la variedad Moscatel fue enviada, experimentalmente, hacia los mercados extranjeros, pero con resultados desfavorables, por lo que se desestimó su comercialización a gran escala. Sólo a partir de 1922, y en forma eventual, encontramos solicitudes para cultivar variedades de exportación: el bodeguero Santiago Solari cultivó 72 ha de Almería, Pedro Giménez y Malvasía, en Junín (Boletín Oficial de la Provincia de Mendoza, Dto. núm. 119, 7 de julio de 1922, p. 3602) y Acacio Vallejo, dos hectáreas, que se encontraban en etapa experimental en la Escuela de Vitivinicultura y habrían sido introducidas por el establecimiento. El estado de los conocimientos difundidos y la prédica efectuada desde los sectores técnicos permiten inferir cierta influencia para que estos productores iniciaran ensayos con estas variedades.

La información presentada nos permite concluir en la ausencia de estímulos estatales concretos para la extensión de variedades aptas para la exportación de uva en las primeras décadas del siglo Xx. Esta circunstancia amerita que atendamos a los empresarios que tempranamente incursionaron en la actividad animados, probablemente, por intentos de adaptación ante escenarios de oportunidades y de dispersión de riesgos frente a coyunturas cambiantes.

\section{LAS TRAYECTORIAS DE ALGUNOS EMPRENDEDORES}

Por un lado, el bodeguero mendocino Pedro Benegas, hijo de Tiburcio, era propietario de una de las empresas vitivinícolas más importantes de la región -fundada en 1883 (El Trapiche)- y fue uno de los primeros empresarios que experimentó el cultivo de uvas finas para consumo en fresco (San Martín, 1944, p. 5). Pedro Benegas integraba el grupo de empresarios preocupados por una vitivinicultura de calidad, por lo cual se había perfeccionado en Europa, contrataba a personal técnico calificado y realizó experiencias sobre selección varietal durante la primera década de 1910 .

Además, prestó especial atención a los ensayos sobre empaque, traslado y comercialización de variedades para consumo en fresco en el mercado extranjero, a modo de conocer cuáles arribaban en mejores condiciones. Ya en 1904 envió uvas criollas con destino a Londres, pero llegaron en mal estado. Como era costumbre entre los empresarios mejor posicionados, tres años después Benegas hizo un viaje de estudios por Europa (San 
Martín, 1944, p. 10). En esa ocasión, además, adquirió variedades para conformar viñedos experimentales en Mendoza y profundizar los ensayos sobre aclimatación y adaptación a las condiciones ambientales locales.

Las experiencias en sus viñedos dieron como resultado la obtención de una variedad comúnmente denominada Gobernador Benegas (Croce, s. f., p. 178). Así, en 1914, la empresa ofertaba colecciones de barbechos de uva especiales de mesa ${ }^{14}$ y contaba con cámaras frigoríficas propias. ${ }^{15}$ Por entonces, este equipamiento era una verdadera innovación y no estaba al alcance de todos los productores agrícolas, quienes debían alquilar una cámara para conservar la producción. De modo que la posesión de tecnología de avanzada ubicaba a Benegas en un lugar privilegiado y más competitivo respecto a sus pares, por lo que el bodeguero se posicionó como un introductor temprano (1907-1913) de conocimientos, tecnologías y equipamientos que aún no estaban ampliamente extendidos en la provincia, pese a la ausencia de incentivos estatales y del respaldo de las entidades vitivinícolas. Ya en 1925, la bodega Trapiche ofertaba uva seleccionada en embalajes especiales. ${ }^{16}$ Poseía, además, una casa comercial en Buenos Aires que lo vinculaba directamente con los exportadores, prescindiendo así de intermediarios para la comercialización del producto.

El itinerario económico reconstruido aporta elementos para conocer cómo una empresa que tradicionalmente había abastecido al mercado interno -vinos comunes y finos- replanteó su estrategia comercial y orientó recursos a nuevos sectores del mercado de consumo (cultivo de uvas finas para el extranjero), para así controlar prácticamente todos los eslabones de la cadena.

Durante este periodo también entró en escena el español Manuel Ruano, quien llegó al país en 1906 procedente de Málaga para trabajar como administrador en la bodega Bombal. Suponemos que Ruano había adquirido experiencia y conocimientos sobre la materia en su ciudad natal puesto que Málaga era el centro de ventas y de comercialización de las uvas de Almería, ciudad que lideró la exportación de uva en fresco hacia Estados Unidos durante las primeras décadas del siglo XX. A partir de 1913 formó distintos emprendimientos junto con sus hermanos, Juan y José, en los rubros inmobiliarios y vitivinícolas. Ya en la década de 1920 se desvinculó de ellos e inició la compra de propiedades en departamentos con alta densidad de explotaciones vitivinícolas (Guaymallén, Godoy Cruz y Las Heras). Durante estos años, ensayó cultivos de la variedad Almería y poco después se posicionó como su principal exportador, por lo que ha sido

\footnotetext{
${ }^{14}$ Los Andes, 27 de junio de 1914, p. 7.

${ }^{15}$ BCVN, núm. 106, 10 de mayo de 1915, p. 70.

${ }^{16}$ Los Andes, 4 de febrero de 1925, p. 12.
} 
señalado como el introductor de la variedad en Mendoza y Argentina, e impulsor de su comercio internacional. ${ }^{17}$ Otras fuentes también vinculan a la familia Ruano con el cultivo y venta de variedades para exportar. "¿Quiere dólars o esterlinas? Adquiéralas con sarmientos de uvas Almería o Alta Fantasía ${ }^{18}$ que ofrecen Juan A. y José Ruano al precio de \$0.05 en Guaymallén." ${ }^{19}$

De manera que en 1927 la firma poseía terrenos en Guaymallén, Godoy Cruz y Las Heras con una producción anual de 60000 cajones de uvas (Álbum de la Provincia de Mendoza, 1927), la cual había sido premiada en diversos certámenes nacionales. Manuel, una vez desvinculado comercialmente de sus hermanos, se asoció con los bodegueros Bombal y Melero Rodríguez. ${ }^{20}$ En este emprendimiento cultivó variedades Ohanes reconvirtiendo, mediante la técnica del injerto (Rupestris du Lot e híbridos de Berlandieri), viñas de variedades francesa y criolla. ${ }^{21}$ Para la comercialización del producto no disponían de canales directos, por lo que contrataron a un representante de ventas estadunidense.

$\mathrm{Al}$ año siguiente, Manuel Ruano inició viajes esporádicos a Chile y en 1930 poseía propiedades en ese país (fundo San Manuel, provincia de Llay-Llay) "para la explotación de parrales, por el más moderno sistema, para cosechar uvas de exportación", con motivo de la llegada de familias italianas a ese país, tras una breve estadía en Mendoza. ${ }^{22}$ Estos datos confirman, entonces, el conocimiento técnico de que disponía el español sobre el cultivo de estas variedades, adquirido en su país natal y profundizado y adaptado, luego, en Argentina y Chile.

Ese año, el mencionado bodeguero Santiago Solari extendía el cultivo de la variedad Almería a doce hectáreas de su finca Los Olivos (Junín), ${ }^{23}$ lo cual ratifica su participación como temprano experimentador. Recordemos que en 1916 había solicitado autorización oficial para plantar vides de esta variedad. Además, en esa propiedad Solari cultivaba también viñedos para producción de vino (Verdot, Pinot) y ensayaba la introducción de variedades poco conocidas (Raboso, Aspiran Bouchet y Lambrusco).

${ }^{17}$ Revista de la Junta de Estudios Históricos de Mendoza, 1980, p. 169.

${ }^{18}$ Esta era la denominación genérica que recibían las variedades aptas para exportación, con características distintivas respecto de otras variedades para consumo en fresco. El nombre es una traducción al castellano de Extra Fancy, realizada por un técnico del ferrocarril Buenos Aires al Pacífico tras varios viajes a Estados Unidos.

${ }^{19}$ Los Andes, 1 de junio de 1925, p. 6.

${ }^{20}$ En 1927, Bombal y Melero daban cuenta de una producción anual de $45000 \mathrm{hl}$. La firma cultivaba y comercializaba otros frutales en los mercados nacional y extranjero (duraznos, peras).

${ }^{21}$ Revista Mensual del BAP, núm. 92, julio de 1925, p. 23. Otras fuentes también lo indican como el introductor de esta variedad, véase San Martín (1944, p. 13).

${ }^{22}$ El Mercurio, 6 de junio de 2005. Recuperado de http://diario.elmercurio.cl/detalle/index

${ }^{23}$ La extensión de la propiedad era de 259 ha. Archivo General de la Provincia de Mendoza, Protocolo Notarial núm. 2.430 -Touza-, escritura núm. 131, 30 de abril de 1928, f. 515 v. 
Queda demostrada, así, la participación activa de estos emprendedores en la introducción de variedades aptas de consumirse como fruta y para exportar. Es importante mencionar que su difusión en la provincia respondió no sólo a las condiciones ambientales favorables, sino que tuvieron gran incidencia las preferencias del mercado estadunidense y que el gobierno de ese país prohibiera el ingreso de la variedad proveniente de España a raíz de una plaga de ceratitis capitata (comúnmente conocida como mosca del Mediterráneo). Otros datos confirman la extensión de esta variedad y la inclusión de nuevos actores, aunque las fuentes disponibles no permiten cotejar la extensión cultivada con variedades para exportación respecto a la extensión total de viñedos cultivados en la provincia. En 1926 se estimaba que en Mendoza y San Juan 3000 ha estaban cultivadas con uvas de mesa, con un predominio de la última provincia. ${ }^{24}$ $\mathrm{Al}$ año siguiente, varios empresarios ya ofertaban barbechos de esa variedad y varias firmas extranjeras se presentaron en Mendoza interesadas en comprar uvas. ${ }^{25}$ Asimismo, entre 1922 y 1926 registramos la instalación de firmas que comercializaban la producción agrícola en otros destinos, nacionales e internacionales, lo que confirma el dinamismo de la actividad. ${ }^{26}$

Las trayectorias reseñadas demuestran que inicialmente se volcaron al rubro de la exportación de uva en fresco sólo los bodegueros que disponían de capital y que se ubicaban en la Zona Núcleo de difusión de la vitivinicultura moderna. La opción por esta actividad puede interpretarse, por un lado, como una estrategia diversificadora de este subgrupo ante los vaivenes de la economía agrícola provincial, a los estímulos y oportunidades de mercados extranjeros, pero también, como un acoplamiento a los primeros intentos de diversificación frutícola que comenzaban a gestarse en otras provincias, como Río Negro y Neuquén (Bandieri y Blanco, 1991) (véase cuadro 3).

El liderazgo de estos productores se fortaleció, además, en 1928, cuando conformaron la Sociedad de Productores de Uvas de Exportar en una clara estrategia de agremiación para lograr, corporativamente, beneficios para el sector y, a su vez, diferenciarse de la entidad tradicional que representaba a los bodegueros (Centro Vitivinícola Nacional). La misma inició

${ }^{24}$ Revista Mensual del BAP, núm. 83, octubre de 1924, p. 69; Nuestra Tierra, mayo de 1925; Videla (1926, p. 62). Cabe mencionar que Videla era agente de esa empresa ferroviaria en Nueva York. Descendiente de la elite criolla mendocina y probable ingeniero. Entre 1932 y 1935 fue gobernador de la provincia por el Partido Demócrata.

${ }^{25}$ Los Andes, 1 de abril de 1925, p. 10, 3 de septiembre de 1925, p. 9, 11 de agosto de 1926, p. 6, y 19 de diciembre de 1926, p. 7.

${ }^{26}$ Los Andes, 11 de enero de 1922, p. 5. Archivo General de la Provincia de Mendoza, Protocolo Notarial núm. 2132, escritura núm. 210, 28 de junio de 1926, fs. 655 v. y 658. 
CUADRO 3. PRODUCTORES-EXPORTADORES DE UVA, SEGÚN VARIEDAD Y PROCEDENCIA DEPARTAMENTAL, 1924

\begin{tabular}{lccl}
\hline & \multicolumn{2}{c}{ Variedad de uva } & \\
Empresario & Alta Fantasía & Almería & Departamento \\
& & & \\
Benegas Hnos. $^{\mathrm{a}}$ & $\mathrm{x}$ & - & Godoy Cruz \\
Bombal, Melero y Ruano $^{\mathrm{b}}$ & $\mathrm{x}$ & $\mathrm{x}$ & Guaymallén \\
Juan y José Ruano $^{\text {Antonio Martín }}$ & $\mathrm{x}$ & $\mathrm{x}$ & Guaymallén \\
Pedro Bailli $^{\text {Luis Tirasso }}$ & $\mathrm{x}$ & $\mathrm{x}$ & Guaymallén \\
Facundo Gomensoro $^{\mathrm{c}}$ & $\mathrm{x}$ & - & Guaymallén \\
J. B. de San Martín $^{\text {Sabá Z. Hernández }}$ & - & $\mathrm{x}$ & Guaymallén \\
Carmelo Grasso $^{\mathrm{c}}$ & $\mathrm{x}$ & $\mathrm{x}$ & s. d. \\
Suárez Hnos. $^{c}$ & $\mathrm{x}$ & - & Maipú \\
\hline
\end{tabular}

\footnotetext{
${ }^{a}$ Bodegueros y propietarios.

${ }^{\mathrm{b}}$ Bodegueros.

${ }^{\mathrm{c}}$ Propietarios de explotaciones dedicadas a la fruticultura y su industrialización.

Fuente: Ferrocarril Buenos Aires al Pacífico (1924, folleto núm. 8, s. p.).
}

sus gestiones con un activo dinamismo, procurando la disminución de los aranceles de importación, exenciones impositivas y el diseño de una tecnología de preenfriamiento y refrigeración asequibles al grueso de los productores que comercializaban frutas.

\section{LA FORMACIÓN DE UNA NUEVA ENTIDAD SECTORIAL Y SUS INICIATIVAS}

El mundo asociativo y corporativo de los empresarios vitivinícolas ha sido objeto de interés para la historiografía regional (Ospital, 1995, 2013; Barrio, 2006; Bragoni, Olguín, Mateu, Mellado, 2011). Una conclusión relevante es la escasa representatividad que la entidad nacional daba a los intereses e inquietudes de los empresarios locales y la multiplicidad de asociaciones surgidas en torno a la vitivinicultura en tiempos de crisis y de prosperidad como resultado de los intereses fragmentarios y/o contrapuestos de los actores (viñateros, bodegueros integrados, bodegueros trasladistas, viticultores-enólogos) (Barrio, 2010).

Algunos antecedentes de asociaciones de productores de uva para consumo en fresco datan de la década de 1920. El Centro de Viñateros de 
Mendoza, creado en 1916 para la defensa de los propietarios de viñedos, impulsó el fomento de variedades de uva de mesa a través de la transformación de los viñedos con variedades especiales para la exportación. ${ }^{27}$ Meses después solicitó el veto de la ley que gravaba la exportación de uva. ${ }^{28}$ Sin embargo, deberían pasar varios años para que estos pedidos se hicieran viables.

La corporación más representativa del sector se constituyó el 18 de agosto de 1928 como Asociación de Productores de Uvas de Exportar de Mendoza. ${ }^{29}$ Su primer directorio estuvo presidido por José B. de San Martín, secundado por el mencionado Pedro Benegas, e integrado por empresarios interesados especialmente en la diversificación agrícola. Otros miembros destacados de la asociación fueron el agrónomo graduado de la Escuela Nacional de Vitivinicultura, Pedro Anzorena, y los bodegueros Julio M. Chavarría y Leoncio Arizu (San Martín, 1944, p. 19). Entre sus objetivos declaró defender y promover la producción y el comercio de uvas de mesa más aptas de la provincia para el mercado exterior, organizar servicios de inspección en el extranjero ${ }^{30}$-tarea que hasta entonces cumplían los delegados del Ferrocarril Buenos Aires al Pacífico y los técnicos del Ministerio de Agricultura de la Nación- y construir un depósito frigorífico $^{31}$ a fin de resolver uno de los principales problemas del sector en relación con la conservación de la producción. ${ }^{32}$

Es oportuno señalar que la práctica del preenfriamiento como una etapa inescindible del proceso se comenzó a extender sólo cuando se comprendió que su omisión perjudicaba el óptimo estado del producto y afectaba su colocación en el mercado de consumo. Sin embargo, un obstáculo fue el alto costo de esa tecnología. En efecto, durante varios años, sólo Benegas disponía de cámaras propias, por lo que empresas ofertaban el

${ }^{27}$ Los Andes, 28 de julio de 1923, p. 5.

${ }^{28}$ Los Andes, 4 de diciembre de 1923, p. 5.

${ }^{29}$ Una entidad con fines similares se formó en San Juan, la Sociedad Frutícola de San Juan.

${ }^{30}$ En 1929 representó a un consorcio de empresarios mendocinos en Estados Unidos para concretar la venta de la producción local en aquel país. Los Andes, 19 de agosto y 20 de septiembre de 1929 , p. 5.

${ }^{31}$ Los Andes, 20 de agosto de 1928, p. 5.

${ }^{32}$ Desde 1914 diversos actores económicos e institucionales estudiaron técnicas de refrigeración con miras a introducir equipamientos afines en los vagones, así como también ensayos de traslado de frutas entre Mendoza y Buenos Aires, con distintos grados de eficacia en sus resultados. No obstante estos valiosos antecedentes, la concreción más importante al respecto es la que se menciona en este trabajo. Cabe destacar que los problemas de empaque y enfriamiento fueron tratados especialmente durante la III Conferencia Nacional de Fruticultura, celebrada en Mendoza en 1928, donde los expositores apuntaban a una solución cooperativa. Los Andes, 1 de mayo de 1928, p. 4. Dos años después se formó la Sociedad Frigoríficos de los Productores de Uvas de Exportar-Mendoza. 
servicio. ${ }^{33}$ Hacia 1928, cuando el sector había logrado mayor consolidación, una sola firma -Mosso Hnos.- parecía controlar el preenfriamiento de la mayor parte de las partidas, rentando el servicio en forma temporal. Dados los costos que esto implicaba, los empresarios comenzaron a bregar por la construcción de un frigorífico.

De acuerdo con estas demandas, además de la publicación de instrucciones sobre el cultivo de las variedades ${ }^{34}$ más aptas (Almería, Alfonso Lavallée, Corazón de Cabrito, Cornichón Violeta y Blanca, entre otras), la Asociación de Productores de Uvas de Exportar de Mendoza se abocó a la construcción del frigorífico en las inmediaciones de una estación de tren ubicada en la ciudad de Mendoza. Tras un informe sobre preenfriamiento de uvas, ${ }^{35}$ el plan fue concretado en $1931,{ }^{36}$ cofinanciado por el Ferrocarril Buenos Aires al Pacífico. El aporte de la empresa también se tradujo en la incorporación de 70 vagones con ventilación especial, que partirían desde la estación de San Rafael, un importante polo productivo ubicado al sur de la provincia. ${ }^{37}$

Otro aspecto de interés fueron las demandas para que el Estado protegiera al sector e interviniera para reducir las trabas impositivas en el país y en el extranjero. Por un lado, la vitivinicultura se encontraba altamente gravada (Barrio, 2010, pp. 195-222). La legislación mendocina preveía un impuesto a la uva que saliera de la provincia, ya fuera para consumo en fresco o para vinificar. Con esto se buscaba controlar y reducir la elaboración de vino en condiciones fraudulentas en zonas no tradicionalmente productoras y, sobre todo, en el mercado de consumo. Es oportuno, entonces, conocer cuáles eran estos gravámenes. En 1923 la uva que se consumía fuera de la provincia estaba sujeta a un impuesto de 0.40 pesos cada $100 \mathrm{~kg}$. Pero al año siguiente, la Ley 866 gravó con 2.50 pesos el hl de vino y con 1.85 los $100 \mathrm{~kg}$ de uva no vinificada, cada $135 \mathrm{~kg}$, afectando así la uva para consumo en fresco que se enviaba a otros mercados. Por ello, el Centro de Viñateros de Mendoza, avalado por la Cámara Sindical de Comercio y Abasto de Buenos Aires, solicitó ser eximido de ese impuesto, con el argumento de que afectaba la competencia con frutas de otras provincias, especialmente de San Juan. Y agregaba que la venta de la producción en otros mercados funcionaba "como válvula de escape"

${ }^{33}$ Por ejemplo, en 1923 la firma extranjera Félix Rimpler \& Cía. anunciaba la venta de frigoríficos modernos y cámaras para conservar vinos finos, jugo de uva y frutas. Los Andes, 23 de diciembre de 1923, p. 4.

${ }^{34}$ Los Andes, 12 de octubre de 1928, p. 4 . Al año siguiente también se informaba, en el diario de mayor circulación, la fecha y destino de partida de busques. Los Andes, 9 de marzo de 1929, p. 5.

${ }^{35}$ Los Andes, 14 de septiembre de 1929, p. 5.

${ }^{36}$ Como resultado de esta iniciativa, Benegas y Ruano son considerados los forjadores de la industria del frío aplicada a la fruta. Marzo e Inchauspe (1967, p. 169).

${ }^{37}$ Los Andes, 14 de abril de 1929, p. 4. 
en periodos de sobreproducción de la materia prima y/o especulación, con una baja exagerada en el precio de la uva. ${ }^{38}$ Se objetaba, además, que el gravamen afectaba el desarrollo de la industria frutícola. Durante este conflicto fue una de las pocas circunstancias en las que fueron visibilizadas las demandas de los productores, más tarde aglutinados en la Asociación de Productores de Uvas de Exportar. La petición fue rechazada con el argumento de que tal gravamen apuntaba "a la protección de la industria madre de la provincia de la competencia desleal en el mercado de ventas". En efecto, un diario local denunciaba que era una práctica extendida el envío de partidas de uvas de mesa intercaladas con uvas para vinificar, ${ }^{39}$ imposibilitando, así el control de la elaboración fraudulenta. Puesto que la fiscalización de la actividad fue prácticamente una política de Estado seguida por los distintos gobiernos, oligárquicos y lencinistas, liberales y populistas, de la provincia, este tipo de impuestos era "justificado" por algunos sectores de la sociedad.

Por otro lado, los impuestos en las aduanas extranjeras eran considerados un obstáculo para la actividad, no obstante las ganancias promisorias que calculaban los analistas. Así, por ejemplo, una delegación de Mendoza y San Juan viajó a Buenos Aires para solicitar la eliminación o reducción de los gravámenes de uva en Alemania y Uruguay, así como también "una reglamentación especial, ${ }^{40}$ a raíz de las sucesivas dificultades que encontraban las uvas argentinas para ingresar a los mercados extranjeros". Tras la entrevista que mantuvo la delegación con una Comisión del Senado, la respuesta recibida demuestra el interés del Estado nacional en el sector: "la solución de los problemas no depende solamente de la acción de los poderes públicos, sino principalmente de la acción y preocupación de los mismos productores [...] es menester no olvidar, que el esfuerzo inteligente de los particulares, rinde excelentes resultados". ${ }^{41}$

En suma, las críticas de los empresarios del sector apuntaban a tres aspectos: los gravámenes a la uva -de mesa y Alta Fantasía- ${ }^{42}$ y otras frutas de exportación; las altas tarifas tranviarias y la falta de incentivos estatales -desde el Ministerio de Agricultura de la Nación y desde el gobierno

${ }^{38}$ Los Andes, 4, 5, 10, 17 y 25 de febrero de 1924. Recordemos que la vitivinicultura en Mendoza ha estado, históricamente, integrada por una cúspide de bodegueros -con y sin viñedos- que en forma anual imponen al grueso de los productores -viñateros- el precio de la uva, de modo que sólo un sector minoritario de los actores vitivinícolas controlaban las fases agrícola e industrial de la actividad e imponían condiciones de venta al resto de los pequeños viñateros y bodegueros. Richard-Jorba (1998 y 2003).

${ }^{39}$ La Palabra, 9 de febrero de 1924.

${ }^{40}$ Los Andes, 17 de octubre, p. 5, y 29 de noviembre de 1928, p. 2.

${ }^{41}$ Los Andes, 28 de enero de 1929, p. 5.

${ }^{42}$ La Ley 866 estipulaba un impuesto a las uvas que se enviaban fuera de la provincia, eximiendo sólo a las que se vinificaban dentro de la provincia. 
local- para estimular esta nueva fase de la viticultura en la provincia, así como también la escasez de frenos a la importación de fruta extranjera. Resulta oportuno mencionar que estas preocupaciones afectaban a los empresarios frutícolas y vitícolas.

Como respuesta, sólo en octubre de $1928,{ }^{43}$ durante la intervención federal al gobierno del bodeguero lencinista Alejandro Orfila, se operó la primera medida estatal para fomento del sector: eximir del pago de impuesto a las uvas de exportar, variedades Almería y Alta Fantasía. Esta política fue producto de las gestiones de la Asociación de Productores de Uva de Exportar, quienes solicitaban ser eximidos inspirados en la Ley 645 , de 1914, sobre exención impositiva a los vinos de exportación como estímulo para el comercio internacional. Es importante mencionar que el logro de esta iniciativa respondía al peso económico y político que los miembros de la entidad -varios de ellos bodegueros y miembros de la burguesía agroindustrial- tenían en la provincia. En efecto, a poco de constituirse como agremiación empresarial lograron una exención que el resto de los viñateros solicitaban hacía varios años. Como consecuencia de esta medida, pocos meses después el Centro de Viñateros se acopló al reclamo, solicitando la exención para todas las variedades de uvas de mesa. ${ }^{44}$

El gobierno provincial, por entonces intervenido, respondió al petitorio estableciendo una modificación a la Ley 886 y su decreto reglamentario. Por decreto especificó que esta exención se aplicaría a todas las "uvas de mesa" comunes destinadas a su consumo en fresco, e incluía en esta categoría a las siguientes variedades: Alta Fantasía, Sanjuanina, Almería, Criolla Grande, Moscatel y Cereza (Boletín Oficial de la Provincia de Mendo$z a, 2$ de febrero de 1929, p. 551), estas dos últimas, para consumo interno. Es oportuno señalar que las fuentes disponibles aún no nos permiten evaluar el alcance de esta normativa en el incremento de las exportaciones ni del comercio de uvas de mesa en el Litoral argentino. Es probable que la crisis internacional de 1930 y la intervención de las juntas reguladoras en las economías regionales argentinas afectaran una posible repercusión favorable en la aplicación de la norma.

${ }^{43}$ Boletín Oficial de la Provincia de Mendoza, dto. núm. 478, 22 de octubre de 1928, p. 5251.

${ }^{44}$ Los Andes, 19 de enero de 1929, p. 5. 


\section{DEL MERCADO INTERNO A LA EXPORTACIÓN: RESOLVIENDO LOS DESAFÍOS TÉCNICOS DE LA ACTIVIDAD}

La inserción competitiva de la uva mendocina en el mercado internacional implicaba la resolución de "cuellos de botella" sobre aspectos particulares del proceso productivo y de comercialización. En efecto, si bien la provincia tenía una larga tradición en el cultivo de uvas y elaboración de vinos para abastecer el mercado interno, el comercio en plazas foráneas demandaba adaptaciones y requerimientos técnicos que sólo los empresarios mejor capitalizados y en posesión de un conocimiento y equipamientos actualizados podrían afrontar.

En primer lugar, el cultivo de variedades Alta Fantasía implicaba una modificación en torno al sistema de conducción, ya que demandaba un retorno al tradicional emparrado en reemplazo del espaldero y contraespaldera $^{45}$ utilizados comúnmente para uvas para vinificar, debido a que aquel se caracterizaba por un mayor rendimiento.

Ya mencionamos la función clave que tuvieron algunos empresarios en la introducción de variedades aptas para la exportación pero la extensión a gran escala de estos cultivos fue dinamizada a partir del trabajo de otros agentes, como la Escuela Nacional de Vitivinicultura -que funcionaba en la ciudad capital de la provincia desde 1896- y el Ferrocarril Buenos Aires al Pacífico -a través de la instalación de estaciones experimentales y divulgación técnica durante la década de 1920-. Los especialistas vinculados con el establecimiento educativo y la empresa ferroviaria iniciaron sucesivos estudios acerca de variedades que se adaptaran a las condiciones ambientales de la provincia y resistieran los largos traslados hasta el mercado de venta. A manera de antecedente, en 1908 Leopoldo Suárez (1911, pp. 199-207) inició algunos ensayos sobre cultivo de uvas de mesa (Moscatel rosado, Moscatel blanco y uva Cereza) destinadas al mercado argentino. Las variedades europeas mencionadas en el estudio ampelográfico de Suárez no fueron retomadas de lo que inferimos su escasa adaptación a las condiciones ambientales locales y preferencias del consumidor. Hubo que esperar hasta la década de 1920 para el desarrollo de descripciones sistemáticas sobre las variedades más aptas. Al respecto, sostenía Francisco Croce, agrónomo y docente-investigador de la Escuela: "La identificación de variedades de uva de mesa tiene un gran valor económico porque el viticultor puede propagar las variedades que realmente le interesan sin estar supeditado a la suerte, debido a la enorme confusión que existe actualmente en la nomenclatura y autenticidad de las mismas, evitándose las consiguientes pérdidas de tiempo y capital" (Croce, s. f.).

${ }^{45}$ Revista Mensual del BAP, núm. 92, julio de 1925, p. 21. 
En 1922, un informe del agrónomo sanjuanino Carlos Zavalla, director de la Escuela de Vitivinicultura, confirmaba la supremacía de la variedad Almería para conservar un óptimo estado tras largos viajes. ${ }^{46}$ Un estudio complementario fue desarrollado también por el Ferrocarril Buenos Aires al Pacífico. Notamos que las variedades ensayadas por la empresa eran las denominadas criollas (véase cuadro 4), es decir, que el ferrocarril no fue un introductor o innovador en cuanto a las variedades cultivadas, pero sí colaboró activamente en la difusión de técnicas y equipamientos para refrigeración y traslado de la mercadería. Este proceso fue acompañado también por la escuela que ofrecía, a bajo costo, sarmientos de uvas para exportar. $^{47}$

Con posterioridad, la empresa ferroviaria se abocó a la formación de viveros y chacras experimentales. Estos espacios, ubicados en diversas subregiones de la provincia, se destinaban a las experiencias sobre selección y aclimatación de variedades para exportar. Por ejemplo, el vivero que instaló en el departamento Godoy $\mathrm{Cruz}^{48}$ fue conformado con cepas procedentes de las explotaciones de Benegas Hnos. y Cía., y Bombal, Melero y Ruano, es decir, los empresarios pioneros del sector. Allí mismo se vendían estacas de vides Alta Fantasía clasificadas, ${ }^{49}$ procurando la difusión uniforme de los viñedos. Además, la Casa de Luis Costantini ofertaba variedades de vides para exportar injertadas en pie americano,$^{50}$ es decir, resistentes a la filoxera.

En 1922 se hicieron algunas pruebas experimentales enviando uvas a Estados Unidos bajo la supervisión del agente de esa empresa y agrónomo Ricardo Videla. El resultado de esta experiencia fue presentado en la $R e-$ vista Mensual del BAP(Videla, 1922, pp. 31-52), en donde se describían con precisión los diversos sistemas de empaque, y se establecía una correlación entre la variedad de uva y el tipo de empaque. Tras sucesivos envíos, la empresa adaptó un sistema extranjero -utilizado en Sudáfrica- y presentó un sistema novedoso: el cajón "Ferrocarril Buenos Aires al Pacífico"

${ }^{46}$ Las características singulares de la variedad Ohanes, originaria de la provincia Almería -concretamente de la comarca del alto Andarax-, la colocaron en una situación de privilegio indiscutible en el comercio mundial de fruta fresca por sus ventajas comparativas. La uva almeriense, de hollejo duro (piel gruesa), se distingue por su extraordinaria capacidad de conservación. De maduración tardía, su vendimia podía prolongarse durante todo el otoño y parte del invierno. Dichas características favorecieron la obtención de uvas para consumir a largo plazo, capaces de resistir las duras condiciones de transporte de carros, barriles y bodegas de buques a vapor en las que toneladas de esta uva se llevaban a sus lugares de destino en todo el mundo hasta la generalización del transporte refrigerado en la segunda mitad del siglo Xx. Marzo (2005, pp. 67-70).

${ }^{47}$ BCVN, núm. 245, 25 de enero de 1928, s. p.

${ }^{48}$ Los Andes, 9 de junio de 1925 , p. 5. 1925 .

${ }^{49}$ Revista Mensual del BAP, núm. 91, junio, pp. 68-69, y núm. 93, agosto, pp. 25-26, ambos de

${ }^{50}$ BCVN, núm. 273, mayo de 1928. 


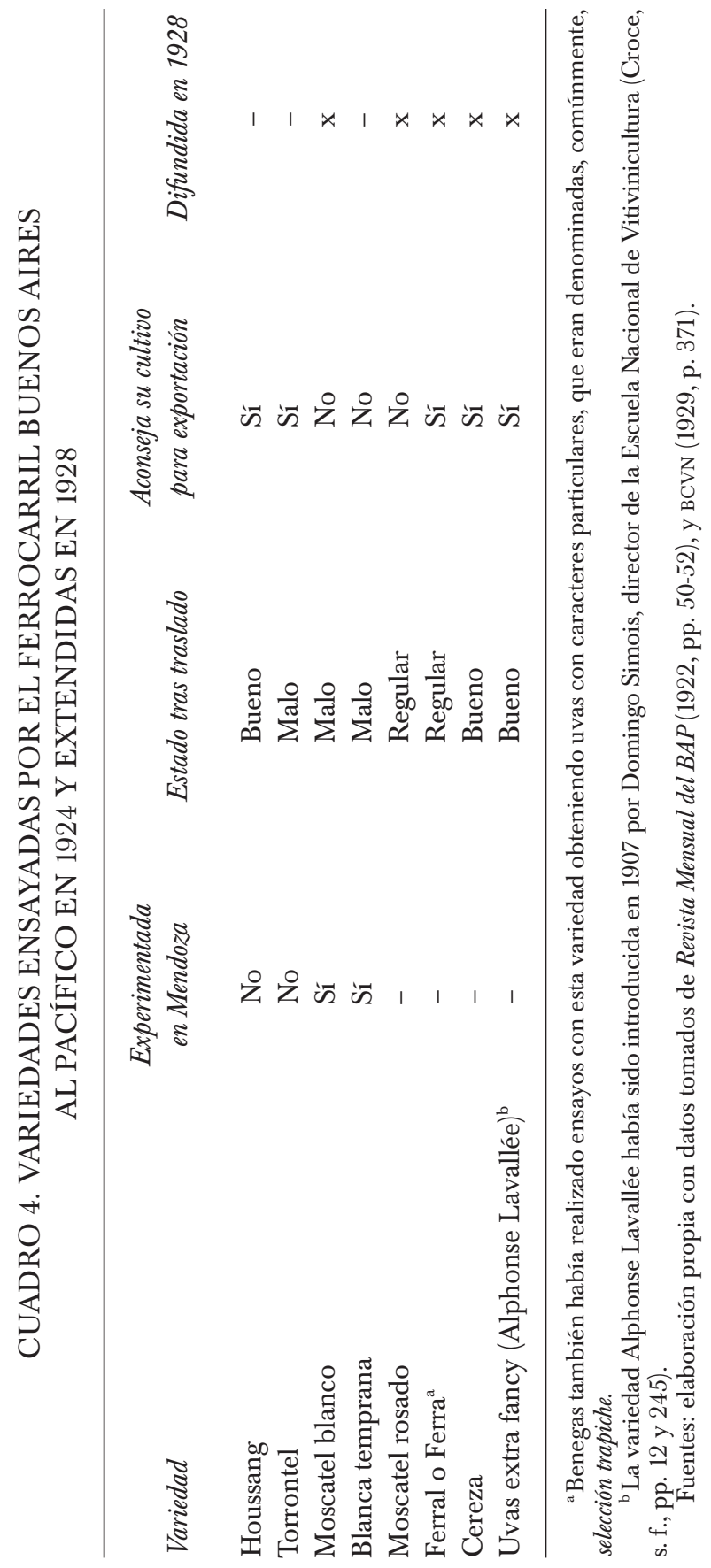


y el "cuyano" (San Martín, 1944, pp. 55, 56 y 144), que se ajustaba a los requerimientos técnicos y económicos de los productores y del mercado consumidor (Rodríguez, 2014a, pp. 179-199). Es oportuno señalar que el acondicionamiento de las uvas en cajones era realizado, mayoritariamente, por mujeres, bajo la dirección de capataces y/o agrónomos regionales, ${ }^{51}$ aunque no siempre en condiciones adecuadas. Aún en 1928 se cuestionaba el trabajo bajo tinglados o parrales, sin posibilidad de resguardar a las trabajadoras ni a la producción del sol. ${ }^{52}$ Esto era aún más necesario tomando en cuenta las deficiencias señaladas para incorporar tecnologías de preenfriamiento de las partidas.

Resueltos estos aspectos de la etapa productiva, restaba entonces abocarse a lograr la comercialización de las partidas en nuevos y distantes mercados.

\section{Los envíos experimentales: Estados Unidos, Inglaterra, Brasil y Uruguay}

La conquista de los mercados internacionales resultaba crucial para la colocación de la producción. Una vez verificadas las variedades más aptas para las condiciones ambientales locales, los actores económicos y estatales iniciaron pruebas experimentales enviando pequeñas partidas al extranjero, con miras a conocer su resistencia al traslado y su aceptación en el mercado. En este proceso registramos iniciativas de empresarios locales, compañías estadunidenses y del Estado, a través de la Escuela Nacional de Vitivinicultura. Estas pruebas experimentales iban a aportar el sustento práctico y técnico para perfeccionar la producción y la posterior comercialización a gran escala.

A modo de antecedente, señalamos que antes de 1910 se enviaron variedades criollas, mediante gestiones de la Compañía Mala Real Inglesa, con buenos resultados (Álbum Argentino Gloriandus, 1910, p. 59 v). Pero los envíos más asiduos, aunque aún con carácter experimental, comenzarían en la década siguiente.

En 1922, la Compañía Argentina de Frutas Elaboradas, de Leonardo Bortoluzzi y José Liciardi, emprendió la fabricación de frutas desecadas para importar desde San Rafael, al igual que el establecimiento Santa Rosa de Andrés Bacigalupo (Guaymallén), que preveía, además, la exportación

${ }^{51}$ Revista Mensual del BAP, núm. 122, enero, p. 51, y núm. 130, septiembre, p. 61, ambos de 1928. La participación femenina en el mercado laboral vitivinícola ha sido analizada en Cerdá (2009) y Vázquez (2008, pp. 189-214, y 2014, pp. 116-131).

52 Revista Mensual del BAP, núm. 134, enero de 1929, p. 50. 
de frutas frescas y pasas de uva. ${ }^{53}$ A su vez, empresarios estadunidenses iniciaron gestiones para exportar uva de mesa a Estados Unidos, y la casa de José y Ángel Peluffo, a Italia. Ese mismo año la Escuela Nacional de Vitivinicultura hizo un envío experimental al mismo destino. ${ }^{54}$ La Junta de Navegación de aquel país ofrecía el traslado gratuito desde Mendoza y la American Trading Company iba a recibir y vender la fruta sin percibir comisión. ${ }^{55}$ Tras esta experiencia, los técnicos extranjeros alertaron sobre la selección y embalaje a los productos (caja tipo sudafricano pero empacada con viruta, sin envoltorio de papel). La firma Melero y Ruano también hizo envíos exitosos de la variedad Almería, y la empresa Benegas Hnos. ensayó el traslado de dos variedades en diversos sistemas de empaque. Como resultado de estas iniciativas, se esperaba que la escuela ofreciera asesoramiento técnico para la resolución de estas dificultades. El Ferrocarril Buenos Aires al Pacífico también organizó envíos y aportaba recomendaciones sobre empaque y etiquetado. ${ }^{56}$ Resulta notorio, entonces, el caudal de información que circuló en torno a estos temas en la Revista Mensual del BAP entre 1922 y 1928. En 1924, además, la empresa confeccionó un registro de productores y exportadores de fruta a Europa y Estados Unidos. ${ }^{57}$ En forma complementaria, técnicos, empresarios e importadores de frutas extranjeros -en especial, estadunidenses- visitaron la provincia durante esos años. ${ }^{58}$ Algunos, incluso se asociaron con empresarios locales para comercializar la producción, lo cual confirma el interés del mercado extranjero en la uva local.

Brasil y Uruguay también se posicionaron como destinos interesantes. La apertura al mercado brasileño, probablemente a partir de las restricciones de las plazas estadunidenses, fue impulsada a través de una exención a la fruta argentina. ${ }^{59} \mathrm{El}$ comercio con Uruguay no se incrementó en este periodo debido a una serie de gravámenes impositivos y cordones sanitarios que afectaban negativamente el comercio de uvas y frutas argentinas. ${ }^{60}$

${ }^{53}$ Comercio e Industria, núm. 53, 12 de febrero de 1922, p. 11. El establecimiento ya funcionaba en 1910 para la fabricación de conservas comercializadas en Mendoza, véase Álbum Argentino Gloriandus (1910, p. 108).

${ }^{54}$ Los Andes, 4 de febrero, p. 5, y 19 de marzo de 1922, p. 5.

${ }_{55}^{5}$ Los Andes, 12 y 15 de enero de 1922, p. 5. Ese mismo año, la empresa envió un representante a la provincia para que se contactara con los viñateros. La Voz de Cuyo, 3 de diciembre de 1922, p. 4.

${ }^{56}$ Revista Mensual del BAP, núm. 55, junio de 1922, pp. 27-39.

${ }^{57}$ Comercio e Industria, núm. 113, 20 de mayo de 1924, p. 7.

${ }^{58}$ Los Andes, 1 de febrero de 1924, p. 5.

59 BCVN, núm. 247, 25 de marzo de 1926, p. 138, y Los Andes, 23 de febrero de 1927, p. 3.

${ }^{60}$ Los Andes, 23 de septiembre, p. 7; 8 de octubre, p. 5, y 5 de diciembre de 1927, p. 5; BCVN, núm. 278, octubre de 1928, p. 533, y núm. 281, enero de 1929, p. 11; La Palabra, 26 de noviembre de 1928 . 
Hacia 1926 estos envíos experimentales habían aportado ya un corpus sólido de conocimientos a los empresarios locales y empresas importadoras acerca de los principales desafíos del traslado y los requerimientos del consumidor. En efecto, un diario local manifestaba que Nueva York y Londres eran "excelentes mercados" para las uvas de mesa mendocinas. ${ }^{61}$ De modo que al finalizar la década varios países se habían consolidado como compradores de uvas argentinas: Estados Unidos e Inglaterra, seguidos por Alemania, Francia, Holanda, Suecia y Dinamarca (San Martín, 1944, p. 13). En función de estimaciones previas (Rodríguez, 2014b, p. 84) entre 1920 y 1928 el envío de uvas hacia el extranjero ascendió de casi 410 toneladas a poco más de 6242 toneladas, es decir, el incremento de las exportaciones de uvas fue de $1422 \%$, con un claro predominio de la producción de uvas sanjuaninas. Estados Unidos concentró casi 50\% del volumen total comprado en el periodo 1921 y 1928, con un ascenso exponencial y continuo de $7000 \%{ }^{62}$ y sólo interrumpido por las restricciones sanitarias de 1927, mencionadas en otro apartado de este trabajo. Aquel país era seguido por Inglaterra, pero con una participación notoriamente menor. De los compradores sudamericanos, sólo Brasil mantuvo un intercambio constante y significativo en todo el periodo, con un incremento de $700 \%$ en las operaciones de compra, representando $32 \%$ del volumen total exportado en esos años (véase cuadro 5).

A partir de entonces, la atención de empresarios y técnicos se orientó a resolver otros problemas: algunos internos, como las altas tarifas de los fletes ferroviarios, la adecuación técnica del sistema de embalaje, control de las plagas y la necesidad de leyes de protección y fomento a la fruticultura que, indirectamente, iban a beneficiar a este subsector. Entre los exógenos, las trabas arancelarias y las restricciones técnicas de los países destino aparecen como los más habituales, como ya mencionamos. Resulta evidente que la atención de estas cuestiones implicaba la participación del Estado.

Por ejemplo, en 1927 la Junta de Horticultura de Washington impuso restricciones a la introducción de uvas y cerezas argentinas, fundamentado en la posibilidad de difundir plagas. ${ }^{63}$ Esto pese a que, en diciembre del año anterior, el Ministerio de Agricultura argentino había declarado las zonas frutícolas argentinas libres de la mosca de los frutos. En relación con esto, la prensa local denunciaba, además, que esta restricción sería la consecuencia de una anterior traba del gobierno argentino para el ingreso de una partida de manzanas proveniente de aquel país. ${ }^{64}$ De todas mane-

${ }^{61}$ Los Andes, 15 de junio de 1926, p. 4.

${ }^{62}$ En 1928 ese país duplicó la compra de uva procedente de Cuyo. BCVN, núm. 278, octubre de 1928 , p. 529 .

${ }^{63}$ Los Andes, 6 y 10 de enero de 1927, p. 5.

${ }^{64}$ La Palabra, 3 de enero de 1927. 

DESDE MENDOZA Y SAN JUAN, EN KILOGRAMOS

\begin{tabular}{lrrr}
\hline Destino & 1920 & 1928 & $\begin{array}{c}\text { Evolución porcentual } \\
\text { en el periodo }\end{array}$ \\
Estados Unidos & 0 & 3315590 & 100 \\
Inglaterra & 0 & 1104200 & 100 \\
Alemania & 0 & 155340 & 100 \\
Brasil & 178954 & 1537880 & 76 \\
Uruguay & 231000 & 95290 & -58 \\
Paraguay & 0 & 34600 & 100 \\
Total & 409954 & 6242900 & 1422 \\
\hline
\end{tabular}

Fuente: Rodríguez (2014b, p. 87).

ras, esta limitación se iba a mantener hasta que el Estado argentino informara oficialmente qué medidas sanitarias adoptaría, e implicaba un serio inconveniente pues la mayor parte de la producción local se orientaba a ese destino, dada la preferencia del consumidor por la variedad Almería. En consecuencia, el Centro Vitivinícola Nacional y la Cámara Sindical de Comercio de Buenos Aires ${ }^{65}$ iniciaron gestiones para derogar tal medida, al igual que el ejecutivo provincial. En respuesta, el Ministerio de Agricultura estableció que todas las partidas de fruta debían llevar un certificado de origen otorgado por la seccional de Defensa Agrícola de Mendoza, organismo que, además, inició una notoria campaña para la curación de frutales en la provincia. Finalmente, el gobierno estadunidense envió al entomólogo Max Kirsluk para que constatara, o descartara, la existencia de la plaga en los cultivos argentinos. ${ }^{66}$ Sólo cuando la gira técnica de Kirsluk arrojó un informe favorable (en marzo), aquel país autorizó el ingreso de uvas de Mendoza, San Juan, Río Negro y Chubut, especificando qué condiciones técnicas debían reunir las partidas. ${ }^{67}$ Esta reconstrucción aporta un claro ejemplo de las desventajas del empresariado local para introducir la producción en el mercado extranjero, no obstante la óptima calidad y la existencia de cuerpos técnicos idóneos que analizaban la sanidad de las

${ }^{65}$ Los Andes, 11 y 25 de enero de 1927, pp. 2 y 5, respectivamente.

${ }^{66}$ Los Andes, 20 y 29 de enero de 1926 , p. 3, 25 de enero y 12 de abril de 1927 , p. 5 , y $L a$ Palabra, 26 de enero de 1927.

${ }^{67}$ Los Andes, 4 de febrero, p. 3, y 5 y 25 de marzo de 1927, p. 5. 
partidas. Este episodio aportó el sustento para que actores estatales y empresarios aunaran criterios técnicos en torno al control de la producción.

Desde entonces se sucedieron diversas acciones con repercusión técnica: en primer lugar, algunos agrónomos del ministerio iniciaron un severo control de la fruta para exportar y en el transporte de la misma; poco después, se reunieron productores y exportadores de fruta de Mendoza, y un delegado del ministerio visitó la provincia para asesorar sobre este tema y sobre cómo sistematizar los controles sanitarios a los cultivos en producción. ${ }^{68}$ Este asesoramiento vino a complementar el servicio que prestaba el agrónomo regional, ingeniero agrónomo Pedro Anzorena. ${ }^{69}$

Simultáneamente, se iniciaron estudios sobre la mosca del Mediterráneo -plaga que no registraba antecedentes en los cultivos regionales, por lo que se desconocía su origen y tratamiento- y una importante acción divulgativa. Por ejemplo, el jefe de la Estación Agronómica de Mendoza aconsejó sobre la prevención de esta plaga, y el director de Defensa Agrícola, sobre parásitos frutales. ${ }^{70}$ Como complemento, el Ministerio de Agricultura de la Nación inspeccionó las provincias productoras de fruta para exportar y declaró a Mendoza, San Juan, Buenos Aires, Río Negro y Chubut libres de mosca del Mediterráneo. ${ }^{71}$ Estas iniciativas permiten matizar los reclamos de los empresarios del sector acerca de la ausencia de atención estatal y valorar la participación del Estado en la solución de un problema técnico que afectaba a los viticultores, en particular, y a los fruticultores, en general.

\section{CONCLUSIÓN}

La reconstrucción presentada muestra los orígenes de un sector de la economía agrícola en Mendoza que no ha sido atendido por la historiografía regional. A partir del seguimiento de los itinerarios económicos de empresarios vitivinícolas que buscaron diversificar sus producciones frente a una actividad presa de crisis cíclicas, sus relaciones con el Estado -provincial y nacional- y las primeras iniciativas para la agremiación sectorial fue

${ }^{68}$ Los Andes, 12, 15 y 16 de febrero de 1927, p. 5.

${ }^{69}$ Los Andes, 19 de julio de 1927, p. 7.

${ }^{70}$ Los Andes, 24 de mayo, p. 3, y 9 de junio de 1926, p. 4. Es oportuno mencionar que estos especialistas se habían formado en la década de 1910 en la Escuela de Vitivinicultura de Mendoza y luego se perfeccionaron en el extranjero, lo cual nos permite confirmar la valoración positiva de la política pública de formación de recursos humanos en la provincia desde el punto de vista del impacto tecnológico en el sector productivo.

${ }^{71}$ Los Andes, 6 de enero de 1927, p. 11. 
posible identificar los inicios de una actividad que se desarrolló desde la década de 1920 y se consolidó aún más a partir de 1930.

La conjunción de capitales y el acceso a técnicas novedosas -empaque y tratamiento poscosecha (preenfriamiento y refrigeración)-, así como la contribución de la empresa Ferrocarril Buenos Aires al Pacífico durante la etapa "experimental" permitieron a este grupo reducido de empresarios, bodegueros y fruticultores desarrollar estrategias de inserción comercial en un sector que hasta entonces era muy marginal para la economía local, carecía de fomento oficial pero recibía estímulos del contexto externo (mercado interesado en el consumo de uva fresca). Es importante remarcar que el desafío fue asumido no sólo a través del reenvío del crónico excedente de materia prima al mercado extranjero, sino con el cultivo y la experimentación de nuevas variedades que se adaptaran a las demandas de los eventuales consumidores y respondieran a los requerimientos técnicos de la comercialización.

Estas estrategias respondieron primero a la iniciativa individual y luego se encauzaron a través de la acción corporativa de la Asociación de Productores de Uvas de Exportar, que buscó obtener beneficios para el sector, independientemente de la injerencia de otras entidades vitivinícolas contemporáneas (Centro Vitivinícola Nacional, Centro de Viñateros, entre otras).

Si bien el fomento estatal no funcionó como recurso dinamizador del sector, sí valoramos su participación en la resolución de problemas técnicos que excedían las competencias de los empresarios y demandaban un corpus científico-técnico más especializado, como por ejemplo, sobre sanidad vegetal y control de plagas. Esto da cuenta, entonces, del manifiesto interés por transformar la fisonomía económica provincial.

Como resultado, observamos en el periodo de estudio la evolución del comercio de uvas en el extranjero, con un marcado predominio de los envíos de ultramar. Para una explicación general del proceso, resta entonces conocer, en futuros abordajes, cómo impactó la crisis de 1930 en el sector y de qué modo repercutió la inauguración del primer frigorífico provincial, en las inmediaciones de una de las estaciones ferroviarias de la ciudad capital de Mendoza, en 1931.

\section{LISTA DE REFERENCIAS}

Álbum Argentino Gloriandus (1910). Número extraordinario dedicado al Sr. Gobernador Dr. Emilio Civit. Mendoza: s. e. 
Álbum de la Provincia de Mendoza (1927). Exposición histórica, política, económica y social. Exteriorización de valores intelectuales y fuerzas vivas que la testimonian como gran provincia. Mendoza: s. e.

Anuario Estadístico de la Provincia de Mendoza (1923-1931). Mendoza, Argentina.

Arrabal de Jameson, M. (2014a). Panorama económico del comercio de uvas y vinos a comienzos de la década del 30. En G. BRIZuela, Hombres, uvas y vinos. II: Aporte para la historia de la vitivinicultura de San Juan 1920-1955. San Juan: Plaza.

Arrabal de Jameson, M. (2014b). El comercio de uvas y vinos y su vinculación con el transporte ferroviario (1930-1955). En G. BRIZUELA, Hombres, uvas y vinos. II: Aporte para la historia de la vitivinicultura de San Juan 1920-1955. San Juan: Plaza.

BALÁN, J. (1978). Una cuestión regional en la Argentina: burguesías provinciales y el mercado nacional en el desarrollo agroexportador. Desarrollo Económico, 18(69), 49-87.

Bandieri, S. y Blanco, G. (1991). La fruticultura en el Alto Valle del Río Negro. Auge y crisis de una actividad capitalista intensiva. Revista de Historia, 2. Recuperado de http://revele.uncoma.edu.ar/htdoc/revele/index.php/historia/article/view/831

BARRIO, P. (2003). Hacia la consolidación del mercado nacional de vinos. Modernización y desarrollo del sector vitivinícola de Mendoza (1900-1914). Espacios, 26.

BARRIO, P. (2006). Las asociaciones de empresarios vitivinícolas mendocinos en tiempos de crisis y expansión económica (1900-1912). En R. Richard-Jorba, E. PÉREZ-Romagnoli, P. BARRIO e I. SANJURJO, La región vitivinícola argentina. Transformaciones del territorio, la economía y la sociedad (1870-1914) (pp. 181-232). Bernal: Universidad Nacional de Quilmes.

BARrio, P. (2010). Hacer vino. Empresarios vitivinícolas y Estado en Mendoza (1900-1912). Rosario: Prohistoria.

BARRIO, P. (2012) ¿Cómo solucionar la crisis vitivinícola? Diagnóstico y propuesta en un informe de 1917. Revista Electrónica de Fuentes y Archivos, 3. Recuperado de http:// www.refa.org.ar/contenido-autores-revista.php?idAutor $=31$

Barsky, O. y Gelman, J. (2001). Historia del agro argentino. Desde la conquista a fines del siglo XX. Buenos Aires: Grijalbo.

Bragoni, B., Olguín, P., Mateu, A. y Mellado, V. (2011). Asociacionismo empresario en el siglo Xx: origen y formación de las entidades vitivinícolas argentinas (pp. 255-278). En A. MATEU (comp.), Vinos y competitividad agroindustrial. Un largo camino. Mendoza: Instituto de Ciencias Humanas, Sociales y Ambientales.

CERDÁ, J. M. (2009). Los censos históricos como fuente para el estudio de la participación femenina en el mercado: el caso de la provincia de Mendoza a comienzos del siglo Xx. Mora (Buenos Aires), 15(1), 53-72.

Croce, F. (s. f.). Primera contribución al conocimiento de las uvas de mesa de Mendoza. Mendoza: s. e.

Day, A., Castillo, S. G. Del, Suárez, L., Lorente, M., Venegas, P., Aguilar, J., et AL. (1917). Contribución al estudio de los problemas económicos, agrarios e industriales de la Provincia de Mendoza. Mendoza: Kraft. 
Di Liscia, M. S. y LuCH, A. (2009). Argentina en exposición. Ferias y exhibiciones durante los siglos XIX y XX. Sevilla: Consejo Superior de Investigaciones Científicas [Colección Universos Americanos].

Girbal-Blacha, N. (1987). Ajustes de una economía regional. Inserción de la vitivinicultura cuyana en la Argentina agroexportadora (1885-1914). Investigaciones y Ensayos, 35, 409-442.

Lacoste, P. (2013). El ferrocarril trasandino y el desarrollo de los Andes Centrales argentinochilenos. 1872-2013. Santiago: Idea.

Lemos, M. (1922). Algunos apuntes sobre la cuestión vitivinícola. Mendoza: Impr. Gutenberg.

Marzo, B. (2005). Antes del milagro el purgatorio. El negocio uvero y la transición económica almeriense. En R. QuirozA-Chrouze (coord.), Los inicios del proceso de democratización. Congreso Internacional Historia de la Transición en España, Almería, España: Universidad de Almería.

Marzo, B. y SÁnchez, A. (2006). La 'uva del barco' en tren. Análisis de una alternativa logística y de mercado para un producto de exportación (1920-1960). TST. Transportes, Servicios y Telecomunicaciones, 11, 116-142.

Marzo, M. e Inchauspe, O. (1967). Geografía de Mendoza [2]. Mendoza: Spadoni.

MÉndez, G. (1982). Repercusiones de la primera guerra mundial sobre la exportación de uva de Almería. Aspectos económicos y demográficos. Cuadernos Geográficos de la Universidad de Granada, 10, 81-96.

Míguez, E. (2008). Historia económica de la Argentina. De la conquista a la crisis de 1930. Buenos Aires: Sudamericana.

Moyano, D. y Rodríguez, F. (2013). Presentación: Detrás de la gran industria. Una aproximación a las actividades manufactureras y extractivas en el interior argentino (1880-1930). H-Industri@: Revista de Historia de la Industria, los Servicios y las Empresas en América Latina, 13, 1-6. Recuperado de http://ojs.econ.uba.ar/ojs/index. $\mathrm{php} / \mathrm{H}$-ind/article/view/565

Nieto Riesco, J. (1926). José Néstor Lencinas (Jefe de Estado). Mendoza: Talleres Gráficos Argentinos L. J. Rosso.

Ospital, M. S. (enero-junio, 1995). Empresarios, dimensión étnica y agroindustrias. El caso del Centro Vitivinícola Nacional (1905-1930). Ciclos en la Historia, la Economía y la Sociedad, 8, 155-166.

Ospital, M. S. (2013). Empresarios vitivinícolas y políticas públicas. Argentina (19051943). En N. Girbal-Blacha y S. DE MendonçA, Corporaciones agrarias y políticas públicas en América Latina, pp. 21-36 Rosario: Prohistoria.

Pérez Guilhou, D. (1980). Emilio Civit. En G. Ferrari y E. Gallo (comp.), La Argentina del 80 al Centenario. Buenos Aires: Sudamericana.

Pérez Romagnoli, E. (2010). Más allá del vino. Industrias derivadas de la vitivinicultura moderna en Mendoza y San Juan. Dinámicas de una región en formación (1885-1930). Rosario: Prohistoria.

Provincia de Mendoza (1925). Recopilación de leyes desde el 1 de enero de 1869 al 31 de diciembre de 1924. Mendoza: Imprenta Oficial. 
Richard-Jorba, R. (1998). Poder, economía y espacio en Mendoza (1850-1900): del comercio ganadero a la agroindustria vitivinícola. Mendoza: Facultad de Filosofía y Letras/ Universidad Nacional de Cuyo.

Richard-Jorba, R. (1999). Modelos vitivinícolas en Mendoza: desarrollo y transformaciones en un periodo secular. En M. Furlani y M. J. Gutiérrez, Mendoza: una geografía en transformación (pp. 185-217). Mendoza: Universidad Nacional de Cuyo.

Richard-Jorba, R. (enero-junio, 2003). El mercado de trabajo vitivinícola en la provincia de Mendoza y los nuevos actores. "El contratista de viña: aproximación a un complejo sistema de empresarios y trabajadores, 1880-1910". Revista Interdisciplinaria de Estudios Agrarios, 18, 5-37.

Richard-Jorba, R. (2010). Empresarios ricos, trabajadores pobres. Vitivinicultura y desarrollo capitalista en Mendoza (1850-1918). Rosario: Prohistoria.

Richard-Jorba, R. (2013). Los frutos del viñedo deberían ser para todos. Depresión y resurrección de la vitivinicultura y aumento de la conflictividad social en Mendoza (Argentina), 1919-1920. Estudios Sociales, 45, 71-101.

Richard-Jorba, R., Pérez-Romagnoli, E., Barrio, P., y Sanjurjo, I. (2006). La región vitivinícola argentina. Transformaciones del territorio, la economía y la sociedad, 18701914. Bernal: Universidad Nacional de Quilmes.

Rodríguez, F. (2013). Opciones diversificadoras se buscan... El temprano fomento de la fruticultura en Mendoza (1900-1918). En M. Ruffini y A. SAlomón, Estado, políticas públicas y ciudadanía en el mundo rural (pp. 19-36). Ciudad Autónoma de Buenos Aires: Imago Mundi.

Rodríguez, F. (2014a). En busca de oportunidades... iniciativas para el consumo de uva fresca en mercados internacionales, Mendoza (1908-1930). En R. RICHARDJorba y M. BONAUdo (coords.), Historia regional. Enfoques y articulaciones para complejizar una historia nacional (pp. 179-198). La Plata: Universidad Nacional de La Plata.

Rodríguez, F. (2014b). ¿Qué hacer con el excedente de uva? Iniciativas y políticas para el consumo de uva fresca en mercados internacionales (1908-1930), Mendoza. En F. RoDRÍGUEz (coord.), Gobernar la provincia del vino. Agroproducción y política entre la regulación y la intervención. Mendoza, 1916-1955 (pp. 71-90). Rosario: Prohistoria.

SAn Martín, J. B. DE (1944). La exportación de uvas con destino a ultramar, 1931-1941. Mendoza: Best Hnos.

SuÁREZ, L. (1911). Contribución a los estudios ampelográficos en la provincia de Mendoza. Mendoza: Imp. y Lit. Nacional.

VÁZquez, M. G. (2008). Trabajo femenino en Mendoza entre fines del siglo XIX y principios del xx. Revista de la Junta de Estudios Históricos, 6-7, 189-214.

VÁZQUEZ, M. G. (septiembre, 2014). Mujeres y vitivinicultura en Mendoza (Argentina) a principios del siglo XX. El caso de Annie Jane Fraser de Innes. RIVAR, 3, 116-131. Recuperado de http://revistarivar.cl/images/vol1-n3/8Vasquez.pdf 
Videla, R. (diciembre, 1922). La exportación de frutas frescas a Norteamérica. Informe sobre los resultados del año 1922 (Conclusión). Revista Mensual del BAP, 61, 31-52.

Videla, R. (1926). Lo que son y lo que valen las provincias de Mendoza y San Juan. Buenos Aires: Peuser.

\section{OTRAS FUENTES}

\section{Hemerografía}

Boletín del Centro Vitivinícola Nacional, Buenos Aires, 1905-1929.

Boletín Oficial Provincia de Mendoza, 1918, 1922, 1928 y 1929, Mendoza, Argentina.

Comercio e Industria, Mendoza, 1922 y 1924.

El Campesino, Sociedad Nacional de Agricultura, Santiago de Chile, 1929.

La Palabra, Mendoza, 1924-1928.

La Voz de Cuyo, Mendoza, 1922.

Los Andes, Mendoza, 1920-1929.

Nuestra Tierra, Buenos Aires, 1922-1929.

Revista Mensual del Ferrocarril Buenos Aires al Pacífico [BAP], Buenos Aires, 1921-1929. 